\title{
Teneke Sac Üreten Bir Firmada Kalite Fonksiyon Göçerimi ile
} Müşteri Gereksinimlerinin Analizi ${ }^{1}$

\author{
Zülal KENGER DİRI
}

Dr. Öğr. Üyesi, Hasan Kalyoncu Üniversitesi, Mühendislik Fakültesi, Endüstri Mühendisliği Bölümü zulal.kenger@hku.edu.tr

Orcid ID: https://orcid.org/ 0000-0002-0114-8870

\section{Zeynep DOĞAN}

Tosyalı Toyo Çelik A.Ş.

zeynepdo6an@gmail.com

Orcid ID: https://orcid.org/ 0000-0003-4073-1222

\section{Eren ÖZCEYLAN}

Doç. Dr., Gaziantep Üniversitesi,

Mühendislik Fakültesi, Endüstri Mühendisliği Bölümü erenozceylan@gmail.com

Orcid ID: https://orcid.org/ 0000-0002-5213-6335

\section{Öz}

İşletmelerin müşteri isteklerini önceden belirlemeleri ve müşterilerine çıkan sonuçlar doğrultusunda hizmet sunmaları büyük önem taşımaktadır. Kalite fonksiyon göçerimi (KFG), müşteriye dayalı kalite yönetimi, müşteri isteklerinin algılanması ve bu hizmeti sunmayı gerçekleştirmek amaciyla kullanılabilecek en uygun yöntemlerden birisidir. Bu nedenle, bu çalışmada teneke sac üretimi yapan bir firmada, müşteri isteklerini karşılamak, müşteri memnuniyetini arttırmak ve bu firmanın piyasadaki rekabet gücünü arttırmak amacıyla KFG tekniği uygulanmıştır. Yapılan analizler sonucunda, KFG metodu kullanılarak yapılan iyileştirmeler ile elde edilen memnuniyet artışının yüksek düzeyde tatmin edici olduğu görülmektedir. Çalışma sonucunda, müşterilerden etkin bilgi almayı sağlayacak anlaş1lır ve kolay uygulanabilir bir uygulama oluşturmanın, müşteri isteklerinin işletmeye taşınmasını kolaylaştıracağı yönünde ortak görüş birliğine varılmıştır. Çalışmanın daha az nitelikli bir firmada gerçekleştirilmesi

\footnotetext{
${ }^{1}$ Makale Geliş/Kabul Tarihi: 28.02.2019 / 22.06.2021

Künye Bilgisi: Kenger Diri, Z., Doğan, Z. ve Özceylan, E. (2021). Teneke sac üreten bir firmada kalite fonksiyon göçerimi ile müşteri gereksinimlerinin analizi. Kahramanmaraş Sütçü Imam Üniversitesi Sosyal Bilimler Dergisi, 18(2), 1191-1203. DOI: 10.33437/ksusbd.533450.
} 
durumunda elde edilecek iyileştirme oranlarının çok daha yüksek olması beklenebilir.

Anahtar Kelimeler: Kalite Fonksiyon Göçerimi, Teneke Sac, Vaka Analizi.

\title{
Analysis of Customer Requirements with Quality Function Deployment in a Tin Plate Manufacturing Company
}

\begin{abstract}
It is of great importance that companies determine customer requests in advance and provide services to their customers in accordance with the results. Quality function deployment (QFD) is one of the most suitable methods for customer-based quality management, perceiving customer requests, and providing this service. For this reason, in this study, in a company that produces tin plates, the QFD technique is applied in order to meet customer demands, increase customer satisfaction and increase the competitiveness of this company in the market. As a result of the analysis, it is observed that the increase in satisfaction achieved with the improvements using the QFD method is highly satisfactory. As a result of the study, it was agreed that creating an easy and understandable application that will enable to receive of effective information from customers will facilitate the transfer of customer requests to the company. If the study is carried out in a less qualified firm, improvement rates can be expected to be much higher.
\end{abstract}

Keywords: Quality Function Deployment, Tin Plate, Case Study.

\section{GİRIŞ}

Günümüzde işletmeler kar oranlarını arttırmak ve piyasada devamlılıklarını sağlamak için birbirleriyle yoğun bir rekabet içine girmişlerdir. Ürün geliştirme, mevcut olan ürünü iyileştirme ve müşterilerin istek ve gereksinimlerine hizlı cevap verebilme yetenekleri, müşteri memnuniyetini sağlamak açısından önemlidir. Son yıllarda yaşanan olağanüstü değişiklikler sonucu küreselleşen dünya tek bir pazar haline gelmiş ve aynı ürünler dünyanın farklı noktalarında üretilir ve tüketilir olmuştur. Böylece farkl1 ülkelerdeki milyonlarca firma birbirlerinin rakibi olmuştur. Bu da küresel üretimi, küresel tüketimi ve küresel rekabeti beraberinde getirmiştir. Hızla değişen dünyada, ancak kendi kuruluşlarını bu değişime hazırlayan, değişimi görebilen ve ayak uydurabilen firmalar ayakta kalabileceklerdir. Küresel rekabet ortamında ayakta kalabilmek için ise kalite ve kalitenin sürekliliği büyük önem taşımaktadır. Literatürde kalite kavramı birçok farklı şekilde tanımlanmıştır. Bunun nedeni aslında kalite 
kavramının kişisel değerler içermesidir. Çünkü kalite; insanların ve kurumların ihtiyaç ve beklentisine göre değişebilmektedir (Annaç Göv, 2018: 394). Kalite Fonksiyon Göçerimi (KFG), müşteriye dayalı kalite yönetimi, müşteri isteklerinin algılaması ve bu hizmeti sunmayı gerçekleştirmek amacıyla kullanılabilecek en uygun yöntemlerden birisidir ve firmaların ürün tasarım süreçlerinde müşteri taleplerini karşılamaya yönelik olarak uyguladıkları bir yaklaşımdır. KFG, müşteri ihtiyaçlarına uygun ürünlerin geliştirilme süresini kısaltarak firmalara sektörde rekabet üstünlüğü sağlar. Bu çalışmada, sac sektöründe teneke sac üreten bir firma için KFG tekniği uygulanmıştır. Uygulamanın amacı, firma için yüksek kalite malzeme üretimini hedeflemek, her geçen gün teknolojik yönünü geliştirerek lider firmalarla eşit düzeye ulaşmak ve bunların sonucu olarak üretim kapasitesini ve müşteri memnuniyeti arttırmak, müşteri şikâyetlerini en aza indirmektir. KFG yöntemi ile birlikte, uygulama yapılan firmada müşteri istek ve ihtiyaçlarına hızlı geri dönüş sağlanacağı düşünülmekte ve böylece müşteri memnuniyetinin artacağı öngörülmektedir.

KFG ilk kez Japonya'da ortaya atılan bir kalite yönetim metodudur. 1984'ten sonra ABD'de de kullanılmaya başlayan bu yöntem, bugün tüm dünyada kabul edilmiştir (Güllü ve Ulcay, 2002: 71). O zamandan beri, birçok yeni fikir ve çalışma ortaya çıkmıştır. Bütün bu çalışmalar Oke (2013) çalışmasında bir araya getirilmiş ve kapsamlı bir literatür taraması sunulmuştur. Tablo 1'de ise 2013'den sonra KFG yönteminin uygulandığı çalışmalar uygulama alanlarına göre incelenmiştir. Tablo 1'den de anlaşıldığ üzere KFG tekniği lojistik, eğitim, sağlık vb. birçok alanda uygulanmış ve gelişen teknoloji ve değişen hayat şartları ile birlikte de kendine yeni uygulama alanları bulacağı düşünülmektedir.

Tablo 1. Literatür incelemesi

\begin{tabular}{ll}
\hline Uygulama alanları & Yayınlar \\
\hline \multirow{3}{*}{ Ürün tasarımı } & Mohanty ve Mahaptra (2013); Zhang vd. (2014); Zaim vd. \\
& $\begin{array}{l}\text { (2014); Aleshkov vd. (2018); Avikal vd. (2018); Kang vd. } \\
\text { (2018) }\end{array}$ \\
\hline \multirow{2}{*}{ Lojistik } & Huang ve Yoshida (2013); Sever (2018); Sofyalığlu ve \\
& Daldır (2019); Sofyalığlu (2020) \\
\hline \multirow{2}{*}{ Turizm } & Erbaş (2016); Shrivastava ve Verma (2014); Behestina ve \\
\hline Eğitim & Azad (2017) \\
\hline Gida & Kelesbayev vd. (2016); Çetinkaya vd. (2019) \\
\hline Tekstil & Jambrak vd. (2018); Kowalska vd. (2018) \\
\hline Bankacılı/Sigorta & Militaru vd. (2014); Tatman (2020) \\
\hline Sağlık & Keçek ve Akıncı (2016) \\
\hline
\end{tabular}




\section{YÖNTEM}

\section{Araştırmanın Amacı, Özgün Değeri ve Modeli}

Çalışmanın amacı, teneke sacı üreten bir firmada KFG yöntemi ile müşteri istek ve ihtiyaçlarını belirleyerek; yüksek kalite malzeme üretimini hedeflemek ve müşteri memnuniyetini arttırmaktır. Bu yönüyle çalışma büyük bir öneme sahiptir. Böylece müşteri memnuniyetinin arttırılması gözlemlenebilir ve sac sektöründe teneke malzeme üretimi yapan firmalar arasındaki rekabet savaşında başarılı olunabilir.

Yapılan literatür incelemesinde teneke sacı üreten bir firmada KFG yöntemi ile müşteri gereksinimlerinin analizi yönünde bir çalışmaya rastlanmamıştır. Literatürde ilk defa çalışılacak olan bu konu çalışmanın özgünlüğünü ortaya koymaktadır.

KFG bir kalite iyileştirme yöntemidir. KFG yöntemi, müşteri istek ve ihtiyaçlarının ürün ya da hizmet karakteristiklerine dönüştürülmesini sağlayarak; kaliteyi artırmayı hedeflemektedir. Bu yöntem müşteri beklentilerinin daha iyi algılanmasını ve memnuniyetinin artmasını sağlar, sürekli iyileştirme için bir alt yap1 oluşturur ve rekabet gücünü arttırır. Bir organizasyonda, KFG sistemi dört aşamada uygulanır. Bu aşamalar (Savaş ve Ay, 2005: 81):

1) Planlama

2) Müşteri beklentilerinin belirlenmesi

3) Kalite evi oluşturulması

4) Sonuçların analizi ve yorumlanmasıdır.

1) Planlama: $\mathrm{Bu}$ aşamada çalışmanın amacı, KFG uygulayacak ekip, uygulamanın zaman dilimi ve süreci belirlenmelidir. Organizasyon ve planlama KFG yönteminin uygulanması sürecinde kritik öneme sahiptir. Projenin planlama süreci iyi hazırlanmaz ise sonuç ve başarı riske girebilir.

2) Müşteri beklentilerinin belirlenmesi: Müssterilerden ürün veya hizmet ile ilgili geri dönüş alınması ve bu bilgilerin, kalitenin artırılması amacıyla kullanılmasıdır. Müşterinin istek ve ihtiyaçlarının belirlenmesi işletmelere ürünlerini veya hizmetlerini geliştirme olanağı tanır. İşletmeler müşteri istekleri ile ilgili elde ettikleri verileri gruplandırarak doğru bir şekilde analizini yapmalıdır.

3) Kalite evi oluşturulması: KFG bir süreçtir, kalite evi ise bu sürecin bir parçasıdır. Bu bölümde KFG’nin "Kalite Evi” inşa edilecek; bir uygulama 
yapılacaktır. Bu aşamada müşteri istekleri ve bu istekleri karşılayacak teknik gereksinimler belirlenerek, aralarındaki ilişki analiz edilir. Bu doğrultuda işletmenin daha iyi kalitede ve müşteri beklentilerini karşılayacak düzeyde üretim yapmasının yolları araştırılır.

Müşteri beklentilerini karşılamak için oluşturulan kaliteli evinin adımları aşağıda verilmiştir:

1. Müşteri beklentilerinin oluşturulması

2. Teknik gereksinimler bölümünün oluşturulması

3. İlişki matrisinin oluşturulması

4. Korelasyon matrisinin oluşturulması

5. Rekabet ve planlama matrisinin oluşturulması

4) Sonuçların analizi ve yorumlanması: Sonuçların analizi yapılarak, elde edilen verilerin yorumlanması aşamasıdır.

\section{Araştırmanın Evreni ve Örneklemi}

$\mathrm{Bu}$ çalışmada demir-çelik sektöründe faaliyet gösteren, kalite güvence sistemlerinin uygulandığı bir firmada teneke sac ürünü için KFG yöntemi uygulanmıştır. Araştırma evreni demir-çelik sektöründe faaliyet gösteren firma müşterileridir. Müşterilerden alınan geri dönüşler doğrultusunda, uzman ekip tarafından, müşteri istekleri ve bu istekleri karşılayacak teknik gereksinimler belirlenmiştir. Müssteri istekleri ve teknik gereksinimler kısaltmaları ile beraber sirasıyla Tablo 2 ve Tablo 3'de gösterilmiştir.

Tablo 2. Müşteri Beklentileri

\begin{tabular}{clc}
\hline 1.Seviye İstekler & 2.Seviye İstekler & Sembol \\
\hline \multirow{4}{*}{ Kalite } & Standartlara Uygunluk & SU \\
& Hatalı Ürün Gönderme Oranı & HÜ \\
& Geri İade Edilen Ürün Oranı & IÜ \\
& Sürekli Kaliteli Ürün & KÜ \\
& Gıda Uygunluğu & GU \\
& Kalınlık Toleransı & KT \\
& Form Verilebilirlik & FV \\
\hline \multirow{2}{*}{ Maliyet } & Ürün Fiyatı & ÜF \\
& Nakliye Masrafları & NM
\end{tabular}




\begin{tabular}{|c|c|c|}
\hline & Satın Almada Fiyat İskontoları & Fİ \\
\hline \multirow{4}{*}{ Teslimat } & Zamanında Teslimat & ZT \\
\hline & Doğru Miktarda Teslimat & DMT \\
\hline & Doğru Ürün Teslimatı & DÜT \\
\hline & Ürünü Sağlam Teslim Garantisi & ST \\
\hline \multirow{4}{*}{ Hizmet } & Ulaşılabilirlik ve Güvenilebilirlik & $\mathrm{U} / \mathrm{G}$ \\
\hline & Servis, Teknik Destek & TD \\
\hline & Fiyat Tekliflerine Zamanında ve Doğru Cevap Verme & FT/ZC \\
\hline & İşi Alma İsteği & İS \\
\hline \multirow{2}{*}{ Esneklik } & Ulaşılabilirlik ve Güvenilebilirlik & $\mathrm{DA}$ \\
\hline & Talep Artışlarında Malzeme Temini & $\mathrm{TA}$ \\
\hline $\mathrm{H} 1 \mathrm{z}$ & Üretim Hızı & ÜH \\
\hline \multicolumn{3}{|c|}{ Tablo 3. Teknik gereksinimler } \\
\hline \multicolumn{2}{|c|}{ Teknik Gereksinimler } & \\
\hline \multicolumn{2}{|c|}{ Kalite Sistem Belgesi } & \\
\hline \multicolumn{2}{|c|}{ Finansal Gücü ve İstikrarı } & \\
\hline \multicolumn{2}{|l|}{ Teknik Kapasite } & \\
\hline \multicolumn{2}{|l|}{ Sektör Deneyimi } & \\
\hline \multicolumn{2}{|c|}{ Lojistik Performans } & \\
\hline \multicolumn{2}{|c|}{ Tedarikçi Firmanın Yönetim ve Organizasyon Kültürü } & \\
\hline \multicolumn{2}{|c|}{ Değişimlere Cevap Verebilme } & \\
\hline \multicolumn{2}{|l|}{ Bilgi Paylaşımı } & \\
\hline \multicolumn{2}{|c|}{ Tedarikçi Güvenirliği } & \\
\hline \multicolumn{2}{|l|}{ Coğrafi Konum } & \\
\hline \multicolumn{2}{|l|}{ Ödeme Kolaylığı } & \\
\hline \multicolumn{3}{|c|}{ Malzemedeki Kusurun Tekrarlanmaması } \\
\hline
\end{tabular}


Elde edilen müşteri isteklerinin, Kalite Evi'nin oluşmasında önemli bir katkısı vardır. Teknik gereksinimler müşteri isteklerine nasıl ulaşılacağını belirler. Teknik gereksinimlerin belirlenmesi; tasarım, işletme ve üretimde kullanılabilmesi için mühendislik diline çevrilmesidir (Savaş ve Ay, 2005: 86). $\mathrm{Bu}$ çalışmada, teknik gereksinimler müşterilerden alınan geri dönüşler dikkate alınarak belirlenmiştir. Müşteri isteklerinin karşılanabilmesi için teknik tanımların doğru bir şekilde belirlenmesi oldukça önemlidir.

\section{Araştırmada Kullanılan Ölçekler ve Analizler}

Şikâyet kartları veya anketler oluşturulması, telefon ile görüşmeler yapılması, odak grupları, kullanım alanlarına giderek direk gözlem yapılması ve paneller müşteri isteklerini belirleme yöntemleri arasında yer almaktadır. Bu çalışmada müşteri istekleri Müşteri Teknik Hizmetleri ekibinin müşteriler ile yaptı̆g 1 toplantılar, elektronik posta veya telefon gibi iletişim araçları ile belirlenmiştir.

Literatürde ilişki derecesi için iki farklı değerlendirme yöntemi vardır. Bu çalışmada, ilişki derecesini atamak için Japon Sistemi kullanılmıştır. Amerikan ve Japon sisteminde kullanılan ilişki derecesi Tablo 4'de gösterilmiştir.

Tablo 4 İlişki derecesi (Savaş ve Ay, 2005)

\begin{tabular}{ccc}
\hline İlişki Derecesi & Amerikan Sistemi & Japon Sistemi \\
\hline GÜÇLÜ & 9 & 5 \\
ORTA & 3 & 3 \\
ZAYIF & 1 & 1 \\
\hline
\end{tabular}

\section{BULGULAR}

İşletmelerin müşteri isteklerini önceden belirlemeleri ve müşterilerine çıkan sonuçlar doğrultusunda hizmet sunmaları büyük önem taşımaktadır. KFG, müşteriye dayalı kalite yönetimi, müşteri isteklerinin algılanması ve bu hizmeti sunmayı gerçekleştirmek amacıyla kullanılabilecek en uygun yöntemlerden birisidir. $\mathrm{Bu}$ çalışmada sac sektöründe teneke sacı üreten bir firma için $\mathrm{KFG}$, tekniği uygulanmıştır. $\mathrm{Bu}$ bölümde oluşturulan kalite evi sonuçları doğrultusunda, işletmenin daha iyi kalitede ve müşteri beklentilerini karşılayacak düzeyde üretim yapmasının yolları araştırılmıştır.

Müşteri istekleri belirlendikten sonra, uzman ekip tarafından bu istekleri karşılayacak teknik gereksinimler belirlenmiş ve aralarındaki ilişkiler puanlanmıştır. Gerekli hesaplamalar yapıldıktan sonra ortaya çıkan sonuçlar Tablo 5'te gösterilmiş ve yorumlanmıştır. 
Tablo 5. Kalite Evi

\begin{tabular}{|c|c|c|c|c|c|c|c|c|c|c|c|c|c|c|}
\hline \multicolumn{15}{|c|}{ Teknik Gereksinimler } \\
\hline Mİ & ÖD & YÖ & KS & FG & TK & SD & LP & YO & CV & BP & TG & CK & ÖK & KT \\
\hline 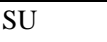 & 9 & 6,08 & 5 & & & & & & & & & & & 1 \\
\hline HÜ & 7 & 4,73 & & & & & & & & & & & & 1 \\
\hline İÜ & 7 & 4,73 & & & & & & & & & & & & 1 \\
\hline KÜ & 7 & 4,73 & & & & & & & & & & & & 1 \\
\hline GU & 9 & 6,08 & & & & & & & & & & & & 1 \\
\hline KT & 9 & 6,08 & 5 & & & & & & & & & & & 1 \\
\hline FV & 7 & 4,73 & & & & & & & & & & & & 1 \\
\hline $\mathrm{U} / \mathrm{G}$ & 8 & 5,41 & & & & & & 1 & 1 & 1 & 1 & & & \\
\hline TD & 8 & 5,41 & & & & & & & 1 & 1 & & & & \\
\hline FT/ZC & 6 & 4,05 & & 3 & & & & & & & & & & \\
\hline İs & 6 & 4,05 & & & & 1 & & & & & & & & \\
\hline ÜF & 6 & 4,05 & & 3 & & & & & & & & & 1 & \\
\hline NM & 4 & 2,70 & & 3 & & & & & & & & 1 & 1 & \\
\hline Fİ & 6 & 4,05 & & 3 & & & & & & & & & 1 & \\
\hline ZT & 7 & 4,73 & & & & & 1 & & & & & 1 & & \\
\hline DMT & 8 & 5,41 & & & & & 1 & & & & & & & \\
\hline DÜT & 7 & 4,73 & & & & & 1 & & & & & & & \\
\hline ST & 7 & 4,73 & & & & & 1 & & & & & & & \\
\hline DA & 8 & 5,41 & & & 5 & & & & 1 & & & & & \\
\hline TA & 6 & 4,05 & & & 5 & & & & & & & & & \\
\hline ÜH & 6 & 4,05 & & & 5 & & & & & & & & & \\
\hline $\begin{array}{l}\text { Teknik } \\
\text { Önem } \\
\text { Derecesi }\end{array}$ & 148 & & 60,81 & 44,59 & 67,57 & 4,05 & 19,59 & 5,41 & 16,22 & 10,81 & 5,41 & 7,43 & 10,81 & 37,16 \\
\hline
\end{tabular}

Yapılan hesaplamalar sonucunda, Tablo 5'teki sonuçlara göre müşteri isteklerini karşılamada en önemli iki unsur kalite sistemi ve teknik kapasite olarak tespit edilmiştir. Bu iki teknik gereksinimi önem sırasına göre firmanın finansal gücü ve istikrarı ve malzemedeki kusurun tekrarlanmaması takip etmektedir. $\mathrm{Bu}$ dört teknik gereksinim üzerinde yapılacak iyileştirmeler firmaya diğer teknik gereksinimlerden daha fazla getiri sağlayacaktır.

Kalite güvence sistemlerini uygulayan işletmeler KFG yaklaşımını da benimsedikleri takdirde müşteri sesini üretime daha hızlı taşıyabileceklerdir. Böylece isteğe göre üretim yaparak rekabette üstünlük kazanabileceklerdir. Bu açıdan düşünüldüğünde bu yaklaşım oldukça önemlidir. Ek olarak, teknik kapasitenin artırılmasının; gelen taleplerin karşılanmasında büyük rol oynayacağ 1 ve böylece müşteriye vaat edilen teslim sürelerinde bir aksama yaşanmayacağ 1 düşünülmektedir. Hatalı ürünler ile ilgili müşteri şikayetlerinin tekrarlanmaması için kullanılan malzemelerin standartlaştırılması ve müşteri takip sistemleri oluşturulması önerilmektedir. Aynı hataların tekrarlanmaması firmaya ciddi bir rekabet üstünlüğü sağlayacağ1 gibi kar oranını da artıracağı öngörülmektedir. 
Firmada üretilen hatasız ürün ve hatalı ürün görselleri Şekil 1 ve Şekil 2'de sırasıyla gösterilmiştir.

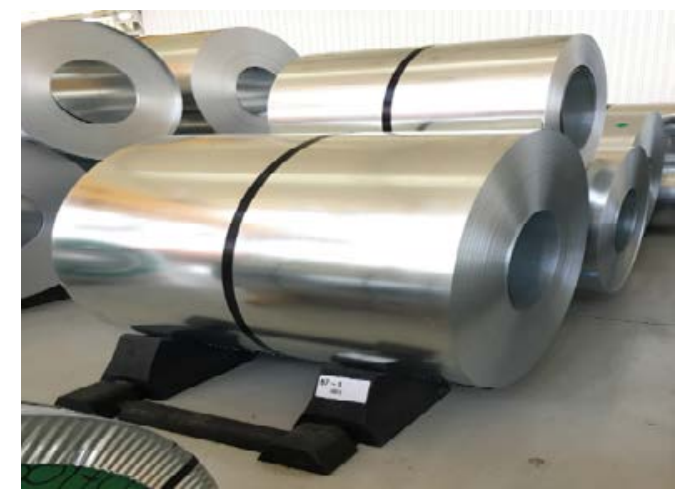

Şekil 1. Hatasız ürün

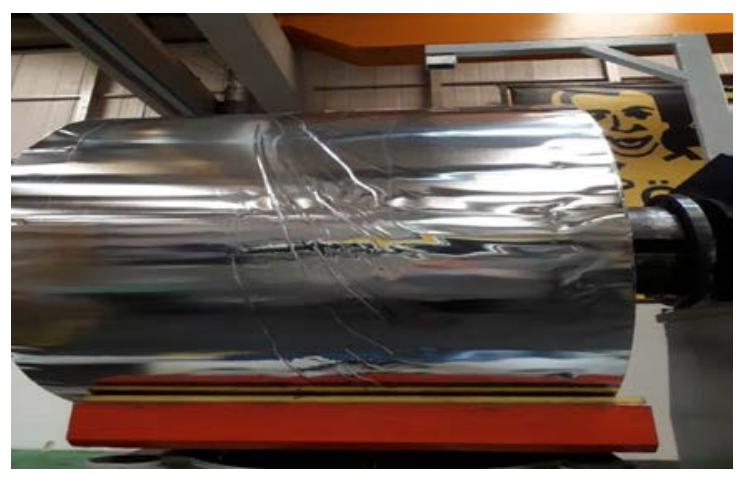

Şekil 2. Hatalı ürün

Ürünün fabrikadan çıktığı gibi sağlam ve hasar görmeden müşteriye teslim edilebilmesi için firma lojistik performanslarında da iyileştirme yapmalıdır. Unutulmamalıdır ki lojistik işletmeler için en önemli unsurlardan biridir. Coğrafik konum zamanında teslimatı engellememeli ve ürün müşterilere hatasız bir şekilde teslim edilmelidir. Yükleme sırasında ürünlerin hasar görmemesi için yükleme kısmında çalışan personele eğitim verilmesi de bu durumun engellenmesi için önerilen yollardan biridir.

Oluşturulan Kalite Evi sonuçlarına göre, firma müşterilerden gelecek her türlü talep değişimlerine uyum sağlayabilmeli ve hızlı cevap verebilmelidir. Bunun için müşteri ile paylaşılacak bilginin yalın olması ve güven konusunda özen gösterilmesi gereklidir.

\section{SONUÇ}


KFG işletmelere rekabette başarı kazandıran bir kalite unsurudur. Çünkü işletmeler bilinçli, ne istediğini bilen müşterilerin etkisi altındadır. Bu etki, işletmeleri, müşteri isteklerini doğru ve hızlı bir şekilde belirleme zorunluluğunda bırakmaktadır. Dolayısıyla daha başarılı olmak isteyen işletmeler müşterileri ile yakın ilişki içinde olmalı, müşteri istek ve ihtiyaçlarını hızlı bir şekilde analiz etmeli ve yeni değişikliklere anında adapte olmalıdır. Ayrıca işletmeler KFG yöntemi ile pazardaki rakiplerinin pozisyonlarını görebildiğinden, önündeki fırsatları ve avantajları değerlendirebilir. Bu durum işletmeye rekabet üstünlüğü kazandırır. Bu uygulama sürecinin katkısı uzun vadede başarılı olmak, müşteri memnuniyeti ve sürekliliğini sağlamak, maliyetleri azaltmak ve üretim hacmini artırmaktır. KFG yaklaşımının işletmelere faydası, müşteri merkezli bir anlayış geliştirmek, müşteri beklentilerini ve ihtiyaçlarını daha iyi analiz etme, ürünün kalitesi ve güvenilirliğini arttırma, müşteri memnuniyeti sağlama, müşteriişletme ilişkilerini geliştirme ve işletmeye uzun vadeli düşünme anlayışı kazandirabilmektedir.

$\mathrm{Bu}$ çalışma, teneke sac üreten bir firmada Kalite Fonksiyon Göçerimi (KFG) yöntemi uygulayarak, firmanın ürün kalitesini ve müşteri memnuniyetini arttırmayı, bununla birlikte; müşteri şikâyetlerini en aza indirmeyi hedeflemektedir.

Elde edilen sonuçlar değerlendirildiğinde; işletmede kalitenin sürekli arttırılması gerektiği anlaşılmış ve bunun firmadaki tüm bölümlerin multidisipliner ve müşteri odaklı bir karar mekanizması geliştirmeleri ile mümkün olabileceği fikrine varılmıştır. Bununla birlikte KFG yaklaşımının temel niteliğini ifade eden "müşteri odaklı bir işletme" olmaları için müşteri teknik hizmetleri bölümünün müşterilerden daha etkin bilgi almalarını sağlayacak anlaşılır ve kolay uygulanabilir bir uygulama oluşturmalarının, müşteri sesinin işletmeye taşınmasını kolaylaştıracağ 1 yönünde ortak görüş birliğine varılmıştır. KFG yaklaşımı, uygulanan firmada ürün bazlı süreç odaklılıktan, müşteri bazlı süreç odaklılığa geçme bilinci oluşturmuştur.

Çalışmanın yapıldığı kuruluşun, çalışma öncesinde etkin bir kalite sistemine sahip olduğu ve kurumsal anlamda müşteri odakl1lığına sahip olduğu düşünüldüğü göz önüne alındığında, KFG metodu kullanılarak yapılan iyileştirmeler ile elde edilen memnuniyet artışının yüksek düzeyde tatmin edici olduğu görülmektedir. Çalışmanın sistemsel anlamda daha az nitelikli bir firmada gerçekleştirilmesi durumunda elde edilecek iyileştirme oranlarının çok daha yüksek olması beklenebilir.

Araştırmanın müşteri istekleri bölümünün sınırlı sayıda katılımcı üzerinde uygulanmış olması çalışmanın en önemli sınırlılığını oluşturmaktadır. Teknik gereksinimleri ve önem derecelerini etkileyen bu faktörlerin farklı açılardan ele 
alınarak, daha da net bir şekilde ortaya koyulabileceği ve geliştirilebileceği düşünülmektedir. Ayrıca KFG metodunun COVID-19 pandemisi ile önemi artan uzaktan eğitim, tedarik zinciri yönetimi ve sağlık hizmetlerinde uygulanması yapılacak yeni çalışmalarla desteklenebilir.

\section{KAYNAKÇA}

Annaç Göv, S. (2018). Havacılık sektöründe kalite sistemi, Kahramanmaraş Sütçü Imam Üniversitesi Sosyal Bilimler Dergisi, 15(2), 391-406.

Aleshkov, A.V., Zhebo, A.V., Kalenik, T. K., and Solovev, D. B. (2018, October 2-4). Quality function deployment method for development of innovative production, Proceedings of the International Scientific Conference "Far East Con", Vladivostok, Russian Federation.

Avikal, S.S., Sing, R. and Rashmi, R. (2018). QFD and Fuzzy Kano model based approach for classification of aesthetic attributes of SUV car profile, Journal of Intelligent Manufacturing, 31, 271-284.

Behestina, M.A. ve Azad, M.F. (2017). A fuzzy QFD approach using SERVQUAL and Kano models under budget constraint for hotel services, Total Quality Management and Business Excellence, 30(7-8), 808-830.

Çetinkaya, C., Kenger, Ö.N., Kenger Diri, Z. and Özceylan, E. (2019, June 2122). Quality Function Deployment Implementation on Educational Curriculum of Industrial Engineering in University of Gaziantep, In: Calisir F., Cevikcan E., Camgoz Akdag H. (eds) Industrial Engineering in the Big Data Era. Lecture Notes in Management and Industrial Engineering. (ss.67-78), Springer, Cham.

Erbaş, E. (2016). Düşünce tarzlarına dayalı kalite fonksiyon göçerimi aracılığıyla hizmet işletmelerine yönelik bir iş değerleme uygulaması, Işsletme Araştırmaları Dergisi, 8(1), 37-55.

Güllü, E. and Ulcay, Y. (2002). Kalite fonksiyonu yayılımı ve bir uygulama, Uludă̆ Üniversitesi Mühendislik-Mimarlık Fakültesi Dergisi, 7(1), 71-91.

Huang, S.T. and Yoshida, S. (2013). Analysis of key factors for formation of strategic alliances in linear shipping company: service quality perspective on Asia/Europe Route after global economic crisis, World Academy of Science, Engineering and Technology International Journal of Economics and Management Engineering, 7(6), 1414-1418.

Jambrak, R.A., Simunek, M., Grbes, F., Mandura, A., and Djekic, I. (2018). Analysis of apple beverages treated with high-power ultrasound: a quality 
function deployment approach, Journal of the Science of Food and Agriculture, 98(6), 2258-2266.

Kang, X., Yang, M., Wu, Y. and Ni, B. (2018). Integrating evaluation grid method and fuzzy quality function deployment to new product development, Mathematical Problems in Engineering, 1-15.

Keçek, G. and Akıncı, Ö.C. (2016) Quality function deployment and an application in an insurance company, International Journal of Academic Research in Business and Social Sciences, 6(4), 111-135.

Kelesbayev, D., Kalykulov, K., Yertayev, Y., Turlybekova, A., and Kamalov, A. (2016). A case study for using the quality function deployment method as a quality improvement tool in the universities, International Review of Management and Marketing, 6(3), 569-576.

Kowalska, M., Pazdzior, M., and Maziopa, A.K. (2018) Implementation of QFD method in quality analysis of confectionery products, Journal of IntelligentManufacturing, 29, 439-447.

Mohanty, P.P. and Mahaptra, S.S. (2013). Design of office chair: A quality function deployment approach, Advanced Materials Manufacturing and Characterization, 3(1), 131-136.

Militaru, C., Burghelea, C., Stefan D.L. and Zanfir, A. (2014). QFD- A modern method of products development in the textile and clothing industry, International Journal of Academic Research in Accounting, Finance and Management Sciences, 4(3), 89-96.

Nursaçan, M.N.N. ve Çetinyokuş, T. (2020) Hastane hizmetlerinin iyileştirilmesinde kalite fonksiyonu göçerimi (KFG) yönteminin kullanılması ve nesnelerin interneti teknolojisiyle model önerisi, Avrupa Bilim ve Teknoloji Dergisi, 20, 181-195.

Oke, S.A. (2013). Manufacturing quality function deployment: Literature review and future trends, Engineering Journal, 17(3), 79-103.

Savaş, H. and Ay, M. (2005) Üniversite kütüphanesi tasarımında kalite fonksiyon göçerimi uygulaması, Dokuz Eylül Üniversitesi Sosyal Bilimler Enstitüsü Dergisi, 7(3), 80-98.

Shrivastava, P. and Verma, D.S. (2014). Application of quality function deployment to improve customer satisfaction in hotel industry, International Journal of Scientific and Engineering Research, 5(6), 957962. 
Sever, M. (2018). Improving check-in (C/I) process: an application of the quality function deployment, International Journal of Quality \& Reliability Management, 35(9), 1907-1919.

Sofyalığlu, Ç. (2020). Bütünleşik KFG yaklaşımı ile sürdürülebilir tedarik zinciri tasarımı: Otomotiv yan sanayinde bir uygulama, Yönetim ve Ekonomi Dergisi, 27(3), 445-477.

Sofyalığlu, Ç. and Daldır, I. (2019). Üçüncü parti lojistik sektöründe depolama faaliyetlerinin stratejik yönetimi: AHS ve KFG yöntemlerinin klasik ve bulanık yaklaşımlar açısından karşılaştırılması, Iş̧letme Araştırmaları Dergisi, 2, 917-936.

Tatman, D. (2020). Bornoz ürün geliştirmede analitik hiyerarşi prosesi ve kalite fonksiyon göçerimi uygulaması, Tekstil ve Mühendis, 27(119), 166-177.

Tripathi, S., Naevor, A. J., Henrekin, L.L., and Welke, K.F. (2019). Design and development of daily morning surgical rounds in ICU by quality function deployment, Pediatric quality \& safety, 4(3), 171.

Zaim, S., Sevkli, M., Camgöz-Akdağ, H., Demirel, Ö.F., Yayla-Yesim A. and Delen, D. (2014). Use of ANP weighted crisp and fuzzy QFD for product development, Expert Systems with Applications, 41(9), 4464-4474.

Zhang, F., Yang, M. and Liu, W. (2014). Using integrated Quality Function Deployment and theory of innovation problem solving approach for ergonomic product design, Computers and Industrial Engineering, 76, 6074. 